\title{
Sensory evaluation and antioxidant capacity as quality parameters in the development of a banana, strawberry and juçara smoothie
}

\author{
Leilson de Oliveira RIBEIRO ${ }^{1 *}$, Juliana Georgia Carvalho dos SANTOS², Flávia dos Santos GOMES 3 , \\ Lourdes Maria Corrêa CABRAL ${ }^{3}$, Daniela de Grandi Castro Freitas SÁ3 ${ }^{3}$, Virgínia Martins da MATTA, \\ Suely Pereira FREITAS ${ }^{1}$
}

\begin{abstract}
In the present study a banana, strawberry and juçara smoothie was developed using an experimental mixture design. The juçara proportion was kept constant while the banana:strawberry ratio varied and the main responses were the sensory acceptability and the antioxidant capacity. From five formulations, only the one with the highest percentage of strawberry was rejected, most likely due to its lower sugar content and higher acidity. In general, panelists chose the sweeter formulations, which were those with a higher percentage of banana. Relating to the consistency, the best formulation was the one containing the same proportion of strawberry and banana pulp, which provided a better flow to the product. Additionally, this sample showed intermediate values of phenolic compounds and antioxidant capacity, as well as desirable physicochemical characteristics. In spite of being possible to obtain four formulations with good sensory acceptance, the one with equal amounts of banana and strawberry pulp is highlighted due to its antioxidant capacity and sensory characteristics, statistically corroborated by the desirability function.

Keywords: anthocyanins; Euterpe edulis; mixture experimental design; functional food; juice.

Practical Application: This study may contribute to increase the added-value of juçara fruit and the availability of a healthy product for consumers.
\end{abstract}

\section{Introduction}

The increase in chronic diseases related to inadequate dietary habits such as the growing consumption of high density foods, many times associated to a sedentary life style, leads to the need of making available to consumers healthier foods as a way of minimizing negative effects associated with the consumption of poor quality diets (Font-Burgada et al., 2016; Moubarac et al., 2017; Moreira et al., 2017).

Fruit products, especially those produced without added sugar, such as dried fruits and $100 \%$ whole juices, can contribute to a healthier diet. A recent survey showed that the market of juices and fruit drinks has presented an important increase in Brazil (Associação Brasileira das Indústrias de Refrigerantes e de Bebidas não Alcoólicas, 2016). Even though the consumption of juices containing higher concentrations of fruits is still low in the country, indicating that there is opportunity for market expansion, particularly for juices having raw material fruits from Brazilian biodiversity.

Fruit blend, according to Brazilian legislation (Brasil, 2009), is the juice obtained from a fruit mixture, fruit and vegetable or the edible part of vegetables and fruit, being an option for a healthy diet as it contains vitamins and oligoelements essential to human metabolism, as well as being an alternative to add value to under-utilized native fruits.

The development of this kind of product presents advantages such as the availability of fruits out of season and the adjustment of the high acidity and low soluble solid content that some fruits contain, allowing to obtain products with higher sensory acceptance besides higher content of bioactive compounds. These characteristics of ready to consume products, rich in nutrients and bioactive substances, meet important demands for consumers such as healthiness and practicality (Bhardwaj \& Pandey, 2011; Nunes et al., 2016).

Among bioactive substances, many have been related to the reduction of the risk of development of non-communicable chronic diseases. One of the most studied is the group of phenolic compounds. These are secondary metabolites found in vegetables and, in some cases, responsible for their color (Haminiuk et al., 2012).

Anthocyanins, a subclass of phenolic group, are pigments responsible for the plants coloration that goes from red to blue and are found in many fruits. Studies have aroused the antioxidant capacity of this substance, being its action attributed mainly to the presence of hydroxyls in its structure (Liobikas et al., 2016). 
Brazil has a great diversity of fruits that are rich in bioactive compounds, such as açai, jamelão, jabuticaba and juçara, which contains relevant amounts of anthocyanins. However, some fruits are still few explored due to their extractive production, high perishability and some undesirable sensory characteristics (Paim et al., 2016; Peixoto et al., 2016).

Juçara (Euterpe edulis Martius), a typical palm from Brazilian Atlantic Forest, produces fruits rich in compounds potentially antioxidants such as the anthocyanins (Bicudo et al., 2014; Schulz et al., 2015). In Brazilian market products containing high amounts of juçara or açaí pulp are very well accepted, which is not observed in the foreign market. The study conducted by Sabbe et al. (2009) is an example of the influence of açaí pulp content in the sensory acceptance of mixed juices. Authors verified that the products formulated with low contents of açaí pulp (4\%) got better scores of overall liking, significantly differing from the product formulated with high content of açaí pulp (40\%). Among the reasons for the rejection, authors cite the higher sweetness as well as the flavor, considered unpleasant in products containing higher percentage of açaí pulp.

Regarding this result, juçara whole pulp is a potential ingredient for new formulations, acting as a natural colorant and also contributing to the levels of antioxidants in a mixed juice, although it is essential to consider the sensory acceptance of formulated products.

Therefore, aiming at obtaining a juice blend that add important characteristics for the market of healthy foods and value to juçara productive chain, the objective of this work was to develop a smoothie from banana, strawberry and juçara, with sensory acceptance and relevant contents of bioactive compounds, using an experimental mixture design.

\section{Materials and methods}

\subsection{Raw materials}

Frozen strawberry pulp (Sempre Viva, Brazil) was acquired in a local market in Rio de Janeiro. Frozen juçara pulp (Juçaí, Brazil) was provided directly from the manufacturing company in the state of Rio de Janeiro. Banana pulp was obtained by de-pulping the fruits in horizontal de-pulper (Bonina $0.25 \mathrm{dF}$, Itametal, Itabuna, Brazil) with $1.5 \mathrm{~mm}$ sieve and polyethylene blades, packed in plastic bags and immediately frozen. Fruits were from Nanica variety in ripeness degree 6, according to the maturation scale described by Aurore et al. (2009). The pulps were maintained in a refrigeration chamber at $-18{ }^{\circ} \mathrm{C}$ until the moment of the use. The commercial pulps were stored considering the expiration date recommended by the producers. In the case of banana, the pulp was stored under freezing for a maximum of one month.

Before using, pulps were defrosted and juçara pulp was pre-treated by centrifugation in basket centrifuge (Model K7165, Thermo Scientific IEC, Bellport, EUA) provided with $100 \mu \mathrm{m}$ nylon filter, aiming at the reduction of suspended solids and lipid fraction that could affect the final product quality due to oxidation and, consequently, rancidity.
Each fruit was chosen based on their individual contribution to obtaining a smoothie without added sugar. Then, banana pulp was responsible for providing sweetness, juçara pulp for their phenolic compounds, especially anthocyanins, and strawberry to balance the mixture $\mathrm{pH}$, reducing the possibility of microorganisms' growth. Aside from these characteristics it is emphasized that bananas and strawberries are fruits with high sensory acceptability, which facilitates the development of new products.

\subsection{Fruit pulps characterization}

Pulps were analyzed for their physicochemical parameters (total solids, $\mathrm{pH}$, soluble solids and acidity), instrumental color, bioactive compounds (total phenolic compounds and anthocyanins) and antioxidant capacity.

\subsection{Smoothie formulation}

In order to define the best formulation a simplex-centroid experimental mixture design (Table 1) was applied. Thus, the juçara pulp proportion was maintained fixed (20\%) and the proportions of banana and strawberry were varied, based in preliminary assays results. The main responses were the sensory acceptability and the bioactive compounds contents (anthocyanins and total phenolic compounds) and the antioxidant capacity. The physicochemical parameters (total solids, $\mathrm{pH}$, soluble solids and acidity) and instrumental color of formulated mixed juices were also analyzed.

The blends were obtained by mixture of the three fruit pulps without adding sugar, followed of standardization in industrial blender (LSP-20, Metalurgica Siemsen Ltda, Brusque, Brazil) and pasteurization in scrapped surface heat exchange (FT25D, Armfield, United Kingdom) at $90^{\circ} \mathrm{C}$ for $35 \mathrm{~s}$, according to the conditions described by Mattietto et al. (2014), considering the similarity of juçara and açaí.

\subsection{Analytical methods}

Sensory analysis

The acceptability test was performed with 100 non-trained panelists, adults, from both genders, chosen among trainees and employees from Embrapa Agroindústria de Alimentos in Rio de Janeiro, Brazil. All panelists are potential consumers of fruit beverages.

Table 1. Experimental mixture design (coded variables) for formulation of the banana, strawberry and juçara smoothie ${ }^{*}$.

\begin{tabular}{ccc}
\hline & Banana pulp & Strawberry pulp \\
\hline F1 & 0 & 1 \\
F2 & 1 & 0 \\
F3 & 0.5 & 0.5 \\
F4 & 0.25 & 0.75 \\
F5 & 0.75 & 0.25 \\
\hline
\end{tabular}

*Juçara pulp proportion fixed in $20 \%$. 
For each smoothie sample, panelists evaluated the global acceptance, which is related to the first impression of the whole product (appearance, flavor, color, taste) and their consistency. Both attributes were measured by a structured 9 point hedonic scale $(9=$ extremely liked, $5=$ did not like or dislike, $1=$ extremely dislike) (Meilgaard et al., 1991).

Codified (three digits) samples were served monadically in $50 \mathrm{~mL}$ plastic cups, at refrigeration temperature, in individual booths, under white light.

This part of the project was approved by the Ethical Committee for Research with Human Beings/RJ linked to Hospital Universitário Clementino Fraga Filho/HUCFF/UFRJ (no 17796813.0.00005257).

\section{Total phenolic compounds}

This determination was performed by spectrophotometry using the Folin-Ciocalteu reagent (Merck ${ }^{\oplus}$, Germany) according to the method described by Singleton \& Rossi (1965) modified by Georgé et al. (2005). The absorbance was measured at $760 \mathrm{~nm}$. A calibration curve was made from Gallic acid standard (Sigma-Aldrich ${ }^{\circledast}$, Brazil), and the blank was prepared with distilled water. Total phenolic compounds content was expressed in $\mathrm{mg}$ GAE.100 g-1 (gallic acid equivalent). The used extracts were obtained by extraction with acetone $70 \%$, followed by filtration. These extracts were diluted 10 times with distilled water.

\section{Total monomeric anthocyanins}

Anthocyanins contents were quantified by differential pH method (Giusti \& Wrolstad, 2001), using cyanidin-3-glucoside as reference, with molar extinction coefficient of $26900 \mathrm{M}^{-1} \mathrm{~cm}^{-1}$ and molecular weight $449.2 \mathrm{~g} \cdot \mathrm{gmol}^{-1}$. The extracts were obtained by dilution of samples in $\mathrm{pH} 1.0$ and $\mathrm{pH} 4.5$ buffer solutions separately. After 30 minutes of their stabilization, the extracts were filtered and the absorbance was read at 510 and $700 \mathrm{~nm}$.

\section{Antioxidant capacity}

The antioxidant capacity was determined by the reduction method of the $\mathrm{ABTS}^{+}$radical (Sigma-Aldrich ${ }^{\circledast}$, Brazil) according to Re et al. (1999). Extraction was conducted in two steps with methanol 50\% and acetone 70\% (Rufino et al., 2007). For the reaction of $30 \mu \mathrm{L}$ of sample was added with $3 \mathrm{~mL}$ de $\mathrm{ABTS}^{+}$. Absorbance was then measured at $734 \mathrm{~nm}$ after 6 minutes of reaction. Results were expressed as micromoles Trolox equivalents per gram $\left(\mu \mathrm{mol}\right.$ TE.g $\left.{ }^{-1}\right)$.

\section{Instrumental color}

The measure of instrumental color was performed in spectrophotometer (ColorQuest XE, Hunterlab, Virginia, EUA) using CIELab/CIELCH with coordinates $\mathrm{L}^{\star}, \mathrm{a}^{\star}, \mathrm{b}^{\star}$, chroma $\left(\mathrm{C}^{\star}\right)$ and Hue angle $\left(\mathrm{H}^{\circ}\right)$ (Ferreira, 1981).

\section{pH, titratable acidity, total and soluble solids}

The analyses were conducted according to the methods recommended by Association of Official Analytical Chemists (2000). For $\mathrm{pH}$ and titrable acidity an automatic titrator was used (785 DMP Titrino, Metrohm, Herisau, Switzerland). Total solids were determined by gravimetry in vacuum oven at $70{ }^{\circ} \mathrm{C}$ (ADP-31, Yamato, South San Francisco, EUA) and soluble solids in portable digital refractometer (Pal-3, Atago, Tokyo, Japan).

\subsection{Statistical analysis}

The analytical results were expressed as mean and standard deviation of measures performed in triplicate. Experimental data were analyzed with Statistica 7.0 software (Statsoft Inc., Tulsa, OK, EUA), using variance analysis (ANOVA), at $\mathrm{p}<0.05$. For estimation of the best formulation the main parameters were considered, taking also in account the technique of simultaneous optimization of independent variables (desirability).

The desirability is based on the conversion of each response, as, in this study, global acceptance, consistency and antioxidant capacity, in an individual desirability function with values defined between zero ( 0 ) and one (1), where 0 corresponds to an undesirable response and 1 to a desirable response (Akhanazarova \& Kafarov, 1982).

\section{Results and discussion}

\subsection{Pulps characterization}

The main characteristics of the raw materials are presented in Table 2. As expected, banana pulp presented the higher content of soluble solids, which is directly related to the sugar concentration in the fruit. This confirms that banana can be a potential source of sugars in the developments of products free of added sugar. Furthermore, among the fruits used in this work, as expected, banana pulp contains also the higher total solids content, corroborating the results observed for soluble solids content.

Regarding the bioactive compounds, a higher concentration of phenolic compounds and higher antioxidant capacity was observed in juçara pulp, which is due, mainly, to its high

Table 2. Physicochemical characteristics, bioactive compounds and antioxidant capacity of banana, strawberry and juçara pulps.

\begin{tabular}{cccc}
\hline Parameter & Banana pulp & $\begin{array}{c}\text { Strawberry } \\
\text { pulp }\end{array}$ & Juçara pulp \\
\hline pH & $4.90 \pm 0.01$ & $3.71 \pm 0.01$ & $4.61 \pm 0.02$ \\
Soluble solids $\left({ }^{\circ}\right.$ Brix) & $23.1 \pm 0.1$ & $5.5 \pm 0.2$ & $5.0 \pm 0.1$ \\
Acidity (g.100 g $)^{-1}$ & $0.27 \pm 0.01$ & $0.58 \pm 0.01$ & $0.23 \pm 0.01$ \\
Total solids $(\%)$ & $22.6 \pm 0.6$ & $5.8 \pm 0.1$ & $9.4 \pm 0.4$ \\
TPC (mg.100 g-1 $)^{2}$ & $28 \pm 2$ & $223 \pm 12$ & $860 \pm 9$ \\
TMA (mg.100 g $\left.)^{-1}\right)^{3}$ & $\mathrm{np}$ & $10.1 \pm 0.1$ & $240 \pm 1$ \\
AC $\left(\mu\right.$ mol Trolox.g $\left.{ }^{-1}\right)$ & $0.50 \pm 0.04$ & $10.0 \pm 0.3$ & $43.3 \pm 2$ \\
$\mathrm{a}^{*}$ & $2.2 \pm 0.2$ & $10.8 \pm 0.5$ & $2.1 \pm 0.1$ \\
$\mathrm{~b}^{*}$ & $6.1 \pm 0.3$ & $-0.12 \pm 0.04$ & $-1.08 \pm 0.03$ \\
$\mathrm{~L}^{*}$ & $41.8 \pm 0.8$ & $36.3 \pm 0.5$ & $29.9 \pm 0.1$ \\
$\mathrm{H}^{\circ}$ & $70 \pm 2$ & $359 \pm 1$ & $332 \pm 1$ \\
\hline
\end{tabular}

${ }^{1}$ Expressed in citric acid; ${ }^{2}$ Expressed in gallic acid; ${ }^{3}$ Expressed in cyanidin-3glucoside. TPC - Total phenolic compounds; TMA - Total monomeric anthocyanin; AC - Antioxidant Capacity; $\mathrm{a}^{*}$ - intensity of red; $\mathrm{b}^{*}$ - intensity of yellow; $\mathrm{L}^{*}$ - luminosity; $\mathrm{H}^{\circ}$ - Hue angle; $\mathrm{np}$ - not performed. 
anthocyanins content represented, in majority, by cyanidin-3rutinoside (Bicudo et al., 2014).

Strawberry pulp presented an intermediate value of phenolic compounds and has stood out by its characteristic acidic $\mathrm{pH}$, also reported by Oliveira et al. (2013). This aspect of strawberries is important in the formulation of blends as it contributes to the microbiological preservation by reducing the blend $\mathrm{pH}$ and acting as a barrier for microorganisms' growth. Moreover, the combination of right proportions of such acidity with other sensory attributes has contributed to balance the flavor of the blend, affecting its acceptance.

Color parameters $\mathrm{a}^{*} \mathrm{e} \mathrm{b}^{*}$ indicate the intensity of red and yellow, respectively. It can be noted that parameter $\mathrm{a}^{*}$, both for strawberry and juçara pulp, is in the range of red color (positive), with more intensity in strawberry pulp. Banana pulp, on the other side, presented a slight yellow color, as parameter $\mathrm{b}^{*}$ was near zero. Luminosity $\left(L^{*}\right)$ was higher in banana pulp and lower in juçara pulp, due to the intrinsic hue of each one.

Parameter $\mathrm{H}^{\circ}$ (Hue angle) belongs to the CIELcH color system that uses coordinates cylindrical instead of Cartesian. In this system, $\mathrm{H}^{\circ}$ refers directly to the sample color, being an important parameter for evaluation products and processes, where $0^{\circ}$ is $+\mathrm{a}^{\star}$ (red), $90^{\circ}$ is $+\mathrm{b}^{\star}$ (yellow), $180^{\circ}$ is $-\mathrm{a}^{*}$ (green) and $270^{\circ}$ is $-\mathrm{b}^{\star}$ (blue). Therefore, as much as close to $0^{\circ}$ is the value, closer to red is the observed color (Minolta, 1991; Lawless \& Heymann, 1999). Also for this parameter, the predominance of the red color for strawberry pulp is observed while for juçara pulp the value is in the range of the violet and purple color. And, as expected, the yellow color for banana pulp, as already demonstrated by CIELab.

\subsection{Smoothie sensory evaluation and bioactive compounds}

Based on the sensory evaluation data (Table 3), it can be noted that, except for formulation 1, all the other smoothie formulations got scores of global acceptance higher than 5 , which characterizes their acceptance. The low acceptance of formulation 1 is probably associated to its higher concentration of strawberry pulp that causes an increasing in its acidity. In general, the scores increased with the increase in banana pulp concentration being formulation 2 the most accepted. Pareto's chart (Figure 1) confirms this trend as it shows the higher effect of banana pulp on the formulated products acceptance. As discussed, banana pulp is the one that contributes most for the sweetness of the blends, which explains the higher score of formulation 2.

The percentage of banana and strawberry pulps presented positive effect on the product consistency. Formulation 3, containing equal amounts of strawberry and banana pulp, presented the higher score (7) for this attribute (Table 3). The combination of pulps in such proportion provided a desirable fluidity to the product, increasing its sensory acceptance.

Pontes et al. (2010), when evaluated the acceptance of commercial grape juice in Brazil, reported a similar result to that obtained in this work, where the samples presenting higher sweetness were the most accepted by the panelists. The same behavior was also observed by Rødbotten et al. (2009), when
Table 3. Sensory acceptance and bioactive compounds of the formulations of banana, strawberry and juçara smoothie.

\begin{tabular}{lccccc}
\hline & $\begin{array}{c}\text { Global } \\
\text { acceptance }\end{array}$ & Consistency & $\begin{array}{c}\mathrm{TPC}^{1} \\
\left(\mathrm{mg} .100 \mathrm{~g}^{-1}\right)^{*}\end{array}$ & $\begin{array}{c}\mathrm{TMA}^{2} \\
\left(\mathrm{mg}^{2} 100 \mathrm{~g}^{-1}\right)^{*}\end{array}$ & $\begin{array}{c}\mathrm{AC} \\
(\mu \mathrm{mol} \\
\text { Trolox.g- })^{*}\end{array}$ \\
\hline F1 & $5 \pm 2$ & $6 \pm 2$ & $3448 \pm 150$ & $498 \pm 3$ & $146 \pm 9$ \\
F2 & $7 \pm 2$ & $6 \pm 2$ & $1310 \pm 43$ & $169 \pm 1$ & $55 \pm 2$ \\
F3 & $6 \pm 2$ & $7 \pm 2$ & $1703 \pm 36$ & $262 \pm 4$ & $74 \pm 4$ \\
F4 & $6 \pm 2$ & $6 \pm 2$ & $2527 \pm 85$ & $369 \pm 2$ & $104 \pm 8$ \\
F5 & $7 \pm 2$ & $7 \pm 2$ & $1628 \pm 33$ & $224 \pm 1$ & $71 \pm 6$ \\
\hline
\end{tabular}

${ }^{*}$ Results expressed in dry basis; ${ }^{1}$ Expressed in gallic acid; ${ }^{2}$ Expressed in cyanidin-3glucoside. TPC - Total phenolic compounds; TMA - Total monomeric anthocyanins; AC - Antioxidant capacity.

evaluating the acceptance of apple juice containing different concentrations of added sugar. In an experiment conducted in Norway and Spain, in both countries they verified that the higher the sugar content the greater the juice acceptance. In the present work, as the sweetness is only due to the sugar composition of the fruits, mainly the banana, without added sugar, the smoothie becomes an alternative for a healthy diet.

The values of phenolic compounds and antioxidant capacity of the smoothies are presented in Table 3 , where it can be observed a correlation between these two variables $(r=0.998, p<0.05)$. As already seen, among the evaluated pulps, juçara presents a higher concentration of phenolic compounds and anthocyanins, which contributes to the high contents of these substances in the blends. In addition, it was verified that the strawberry pulp had a significant contribution to the antioxidant capacity of the smoothies when compared to the contribution of the banana pulp (Figure 1), as this fruit has the lower content of phenolics compounds (Table 3 ).

When considering the concentration of phenolic compounds, which are directly related to the antioxidant capacity, formulation 1 stands out. However, this formulation was rejected in sensory analysis, most likely due to its lower sweetness and higher acidity.

Regarding the contribution of phenolic compounds to health, it is known that their ingestion is recommended as they have been related, in many studies, to the reduction of the incidence of non-communicable chronical diseases such as metabolic syndrome and cancer (Norberto et al., 2013; Verma et al., 2013). Anthocyanins, particularly, are recognized as an anti-inflammatory and antioxidant agent (Carvalho et al., 2015), besides of other protective effects to human body. This further justifies the use of fruits that are rich in these compounds for the development of new products, which contributes also to their added-value as well as to a healthier diet.

A technological function of using fruits rich in anthocyanins, like juçara, is the possibility of not using artificial colorants in the products development. Its intense and typical color generate attractive products both from a sensory and health point of view, as artificial colorants have been related to allergenic diseases (Brasil, 2007) and also to the development of attention deficit hyperactivity disorder, topical dermatitis, hepatic toxicity, among others (Vojdani \& Vojdani, 2015). 


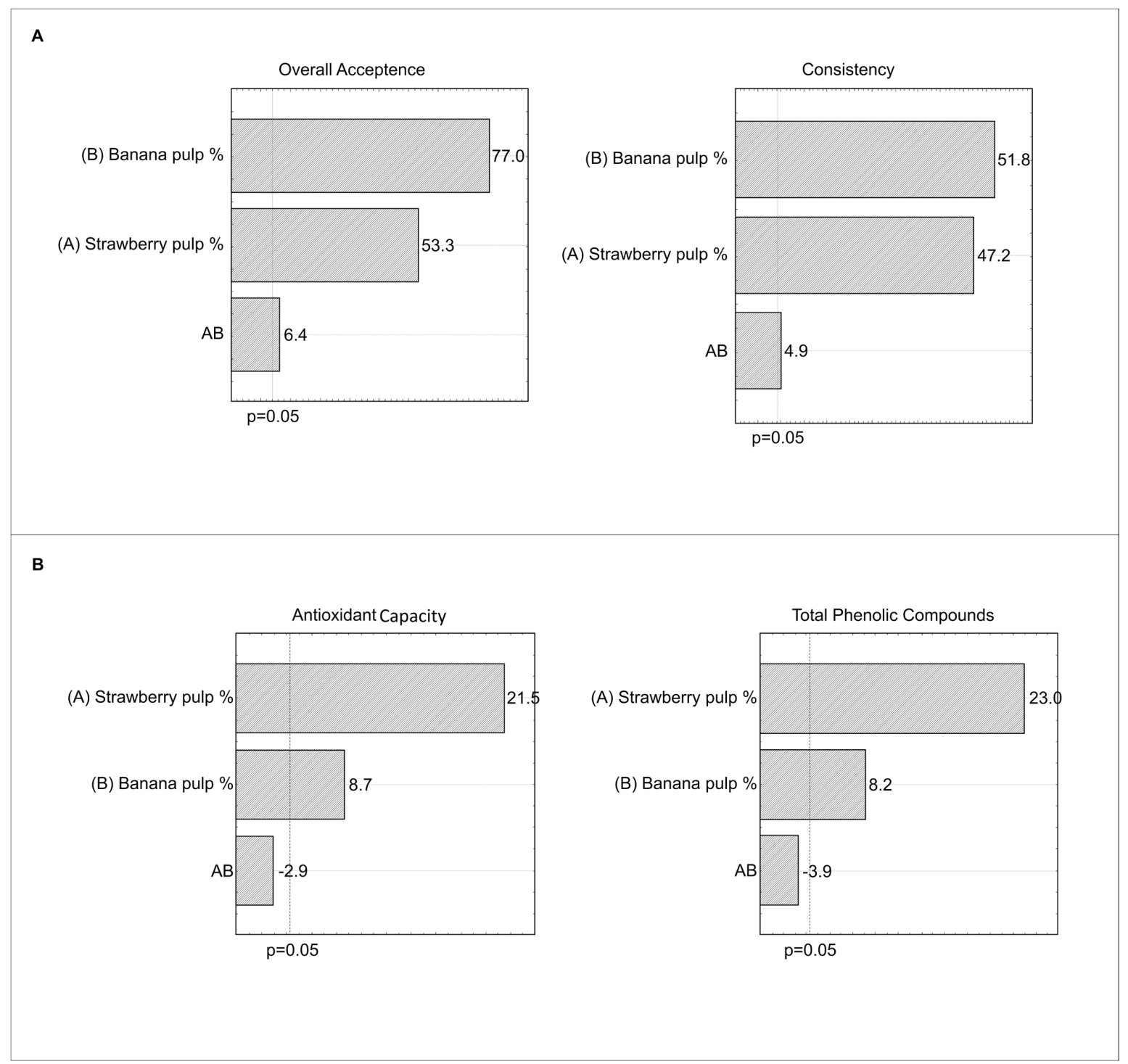

Figure 1. Effect of percentages of banana and strawberry pulps in the acceptance and consistency (A) and antioxidant capacity and total phenolic compounds (B) of the smoothie formulations.

\subsection{Instrumental color and physicochemical characteristics}

It can be noted, among the color parameters evaluated (Table 4), that the luminosity of the samples was between 27 e 31 , low values, as expected due to the characteristic colors of juçara and strawberry.

With respect to Hue angle $\left(\mathrm{H}^{\circ}\right)$, values were in the range that comprises the red color, presenting low variation among the formulated juices. This suggests little effect of the percentage of banana pulp in the final color of the products, highlighting the colors of strawberry and juçara pulps.

Regarding the color intensity $\left(\mathrm{C}^{\star}\right)$, it was higher in the formulations with higher amount of strawberry (formulations 1 and 4). However, like the other color parameters, little variation was observed in the evaluated formulations. Considering the instrumental color, it was observed that the pulps combination visually favored the formulated products.
Table 4. Physicochemical characteristics and color parameters of the formulations of banana, strawberry and juçara smoothie.

\begin{tabular}{lcccccc}
\hline & $\mathrm{L}^{*}$ & $\mathrm{H}^{\circ}$ & $\mathrm{C}^{*}$ & $\mathrm{pH}$ & $\mathrm{SS}$ & Acidity $^{1}$ \\
\hline F1 & $30.2 \pm 0.2$ & $355.3 \pm 0.1$ & $4.9 \pm 0.1$ & $3.92 \pm 0.01$ & $8.6 \pm 0.1$ & 0.45 \\
F2 & $27.4 \pm 0.2$ & $356.0 \pm 0.2$ & $4.6 \pm 0.4$ & $4.32 \pm 0.01$ & $15.4 \pm 0.1$ & 0.36 \\
F3 & $31.0 \pm 0.2$ & $355.2 \pm 0.7$ & $4.7 \pm 0.1$ & $4.11 \pm 0.01$ & $12.1 \pm 0.1$ & 0.41 \\
F4 & $29.1 \pm 0.3$ & $354.8 \pm 0.4$ & $5.6 \pm 0.2$ & $4.04 \pm 0.06$ & $10.6 \pm 0.1$ & 0.43 \\
F5 & $31.0 \pm 0.2$ & $355.3 \pm 0.5$ & $4.1 \pm 0.2$ & $4.20 \pm 0.02$ & $13.9 \pm 0.1$ & 0.38 \\
\hline \multicolumn{7}{l}{$\mathrm{L}^{*}$ - luminosity; $\mathrm{H}^{\circ}$ - Hue angle; $\mathrm{C}^{*}$ - chroma; SS - soluble solids ( ${ }^{\circ}$ Brix); ${ }^{\text {'Expressed in }}$} \\
mg citric acid. $100 \mathrm{~g}^{-1}$.
\end{tabular}

All the formulations presented low pH, below 4.35 (Table 4), which is a barrier for microorganisms growth. The contribution of low $\mathrm{pH}$ for the microbiological stability of fruit juices has been reported by Wang et al. (2016) and Février et al. (2017).

In addition, blends were pasteurized to assure the microbiological quality as heat treatment reduces the initial microbial load while 
it contributes to sensory quality by inactivating the oxidative enzymes (Santhirasegaram et al., 2015).

As previously discussed, the soluble solids contents of the blends confirm the contribution of banana to the sweetness of the formulations and, as expected, it was lower in the product with higher amount of strawberry pulp (formulation 1). In addition to the higher acidity, it has, possibly, resulted in the rejection of this specific sample.

\subsection{Desirability function}

In Table 5 the main parameters used for optimizing the formulation are presented: the low and high limits, the median values and, in parentheses, the desirability of these limits, where zero represents the undesirable values and one the desirable ones. Values of $s$ and $t$ exponents determine the importance of each factor in optimization process. In this work value one was attributed to these parameters in all responses, as they have the same relevance for obtaining a fruit juice blend with sensory acceptability and antioxidant capacity.

The simultaneous optimization of sensory evaluation responses (global acceptance and consistency) and antioxidant capacity of the formulations suggested that the best interaction of these responses, among the evaluated samples, occurred when the smoothie was prepared with equal amounts of banana and strawberry pulp, which to the codified independent variables corresponds to level 0.5 for the percentages of both pulps.

The value of desirability (0.6) after fitted data, presented in Figure 2, corresponds to the acceptable range, according to the criteria of Akhanazarova \& Kafarov (1982), even if it is below the range recognized as excellent ( 0.8 to 1.0 ), according to the same authors. However, this tool proved to be adequate to reinforce the choice of the best percentage interaction of banana and strawberry pulps $(0.5: 0.5)$ to the preparation of the blend.

Table 5. Parameters for optimizing the responses of the formulations of banana, strawberry and juçara smoothie.

\begin{tabular}{ccrccc}
\hline Responses & Low limits & $\begin{array}{c}\text { Median } \\
\text { value }\end{array}$ & High limits & $\mathrm{s}$ & $\mathrm{t}$ \\
\hline Acceptance & $4.7(0)$ & $5.8(0.5)$ & $6.9(1)$ & 1 & 1 \\
Consistency & $5.7(0)$ & $6.2(0.5)$ & $6.8(1)$ & 1 & 1 \\
$\begin{array}{c}\text { Antioxidant } \\
\text { capacity }\end{array}$ & $54.7(0)$ & $100.2(0.5)$ & $145.8(1)$ & 1 & 1 \\
\hline $\mathrm{s}$ and $\mathrm{t}$ - exponents determine the importance of each factor in optimization process.
\end{tabular}
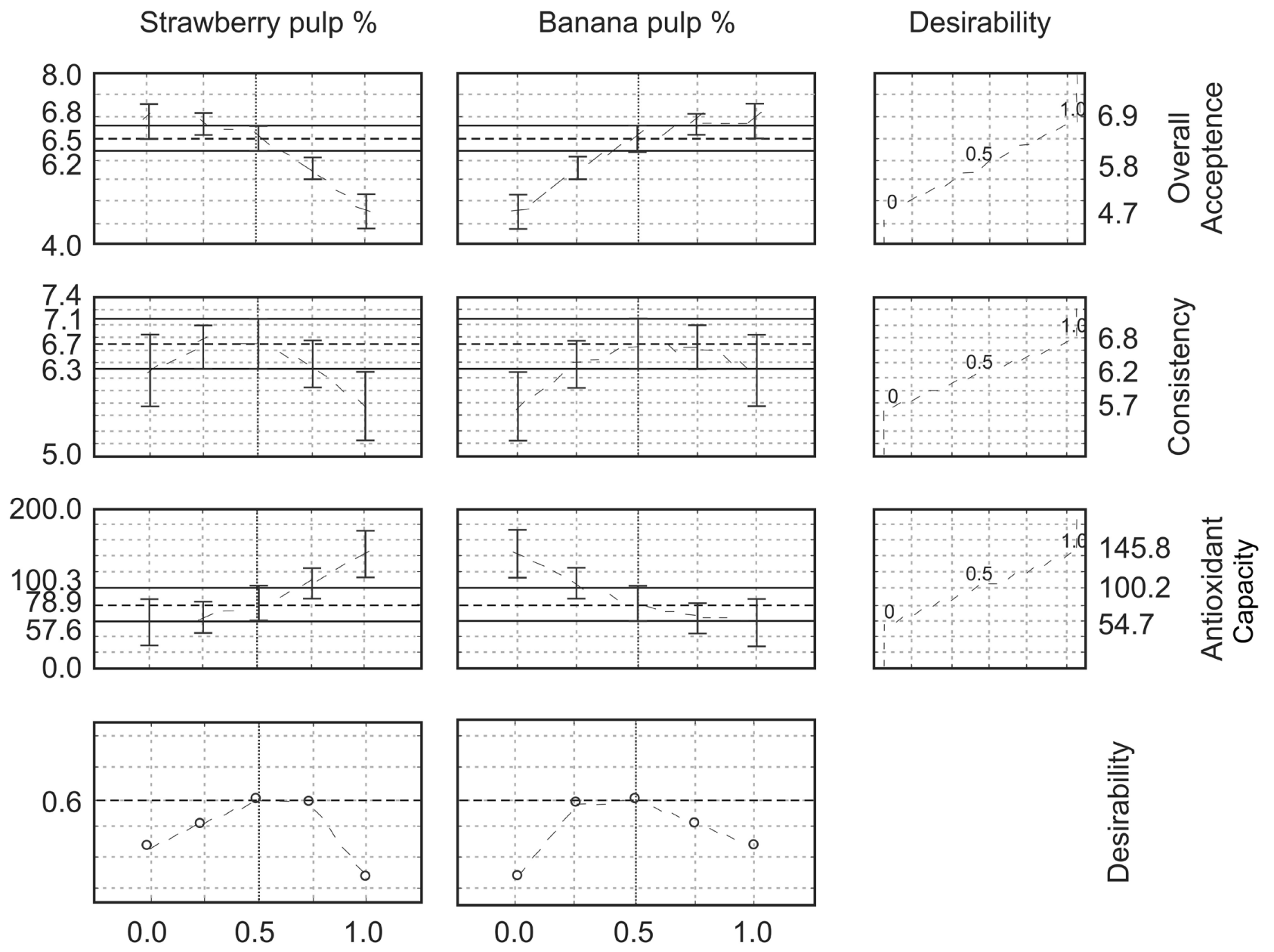

Figure 2. Profile of estimated values and desirability for the responses sensory acceptance, consistency and antioxidant capacity of the formulations of banana, strawberry and juçara smoothie. 


\section{Conclusions}

The applied mixture experimental design permitted to obtain four formulations of a banana, strawberry and juçara smoothie with sensory acceptance and relevant values of antioxidant capacity. The choice of the best blend was performed considering both the acceptance scores and potential functional properties of the smoothie, which indicates blend 3, containing equal amounts of banana and strawberry pulps, as the most promising. This product development may contribute to valorization of juçara productive chain.

\section{Acknowledgements}

The authors thank Capes for the PhD scholarship and also the institutions Federal University of Rio de Janeiro and Embrapa Agroindústria de Alimentos.

\section{References}

Akhanazarova, S., \& Kafarov, V. (1982). Experiment optimization in chemistry and chemical Engineering. Mir Publishers.

Associação Brasileira das Indústrias de Refrigerantes e de Bebidas não Alcoólicas - ABIR. (2016). Dados estatísticos. Brasília: ABIR. Retrieved from http://abir.org.br/o-setor/dados/

Association of Official Analytical Chemists - AOAC. (2000). Official methods of analysis. Washington: AOAC.

Aurore, G., Parfait, B., \& Fahrasmane, L. (2009). Bananas, raw materials for making processed food products. Trends in Food Science \& Technology, 20(2), 78-91. http://dx.doi.org/10.1016/j.tifs.2008.10.003.

Bhardwaj, R. L., \& Pandey, S. (2011). Juice blends: a way of utilization of under-utilized fruits, vegetables, and spices: a review. Critical Reviews in Food Science and Nutrition, 51(6), 563-570. PMid:21929332. http://dx.doi.org/10.1080/10408391003710654.

Bicudo, M. O. P., Ribani, R. H., \& Beta, T. (2014). Anthocyanins, phenolic acids and antioxidant properties of juçara fruits (Euterpe edulis M.) along the on-tree ripening process. Plant Foods for Human Nutrition, 69(2), 142-147. PMid:24570272. http://dx.doi. org/10.1007/s11130-014-0406-0.

Brasil, Ministério da Saúde. Agência Nacional de Vigilância Sanitária - ANVISA. (2007, July 24). Considerações sobre o corante amarelo tartrazina (Informe Técnico n 30, de 24 de julho de 2007). Diário Oficial [da] República Federativa do Brasil.

Brasil, Ministério da Agricultura, Pecuária e Abastecimento. (2009, June 4). Regulamenta a Lei no 8.918, de 14 de julho de 1994, que dispõe sobre a padronização, a classificação, o registro, a inspeção, a produção e a fiscalização de bebidas (Decreto $\mathrm{n}^{\circ} 6.871$, de 4 de junho de 2009). Diário Oficial [da] República Federativa do Brasil.

Carvalho, F. B., Gutierres, J. M., Bohnert, C., Zago, A. M., Abdalla, F. H., Vieira, J. M., Palma, H. E., Oliveira, S. M., Spanevello, R. M., Duarte, M. M., Lopes, S. T., Aiello, G., Amaral, M. G., Pippi, N. L., \& Andrade, C. M. (2015). Anthocyanins suppress the secretion of proinflammatory mediators and oxidative stress, and restore ion pump activities in demyelination. The Journal of Nutritional Biochemistry, 26(4), 378-390. PMid:25632845. http://dx.doi. org/10.1016/j.jnutbio.2014.11.006.

Ferreira, V. L. P. (1981). Princípios e aplicações da colorimetria em alimentos. Campinas: ITAL.

Février, H., Le Quéré, J., Le Bail, G., \& Guyot, S. (2017). Polyphenol profile, $\mathrm{PPO}$ activity and $\mathrm{pH}$ variation in relation to colour changes in a series of red-fleshed apple juices. Lebensmittel-Wissenschaft + Technologie, 85, 353-362. http://dx.doi.org/10.1016/j.lwt.2016.11.006.

Font-Burgada, J., Sun, B., \& Karin, M. (2016). Obesity and cancer: the oil that feeds the flame. Cell Metabolism, 23(1), 48-62. PMid:26771116. http://dx.doi.org/10.1016/j.cmet.2015.12.015.

Georgé, S., Brat, P., Alter, P., \& Amiot, M. J. (2005). Rapid determination of polyphenols and vitamin C in plant-derived products. Journal of Agricultural and Food Chemistry, 53(5), 1370-1373. PMid:15740008. http://dx.doi.org/10.1021/jf048396b.

Giusti, M. M., \& Wrolstad, R. E. (2001). Characterization and measurement of anthocyanins by UV-visible spectroscopy. In R. E. Wrolstad (Ed.), Current protocols in food analytical chemistry (unit F1.2, pp. 1-13). New York: John Wile.

Haminiuk, C. W. I., Maciel, G. M., Plata-Oviedo, M. S. V., \& Peralta, R. M. (2012). Phenolic compounds in fruits: an overview. International Journal of Food Science \& Technology, 47(10), 2023-2044. http:// dx.doi.org/10.1111/j.1365-2621.2012.03067.x.

Lawless, H. T., \& Heymann, H. (1999). Sensory evaluation of food. Maryland: Aspen Publishers.

Liobikas, J., Skemiene, K., Trumbeckaite, S., \& Borutaite, V. (2016). Anthocyanins in cardioprotection: A path through mitochondria. Pharmacological Research, 113(Pt B), 808-815. PMid:27038533. http://dx.doi.org/10.1016/j.phrs.2016.03.036.

Mattietto, R. A., Gomes, F. S., \& Matta, V. M. (2014). Effect of açaí pasteurization conditions on its antioxidant activity. Acta Horticulturae, (1), 179-185. http://dx.doi.org/10.17660/ActaHortic.2014.1040.23.

Meilgaard, M., Civille, G. V., \& Carr, B. T. (1991). Sensory evaluation tecniques. Boca Raton: CRC Press.

Minolta. (1991). Chroma Meter CR-300/CR310/CR-321/CR-331/CR331C. Tokyo. Instruction manual.

Moreira, R. M., Martins, M. L., Leite, B. R. C. Jr., Martins, E. M. F., Ramos, A. M., Cristianini, M., Campos, A. N. R., Stringheta, P. C., Silva, V. R. O., Canuto, J. W., Oliveira, D. C., \& Pereira, D. C. S. (2017). Development of a juçara and Ubá mango juice mixture with added Lactobacillus rhamnosus $\{\mathrm{GG}\}$ processed by high pressure. Lebensmittel-Wissenschaft + Technologie, 77, 259-268. http://dx.doi. org/10.1016/j.lwt.2016.11.049.

Moubarac, J.-C., Batal, M., Louzada, M. L., Martinez Steele, E., \& Monteiro, C. A. (2017). Consumption of ultra-processed foods predicts diet quality in Canada. Appetite, 108, 512-520. PMid:27825941. http:// dx.doi.org/10.1016/j.appet.2016.11.006.

Norberto, S., Silva, S., Meireles, M., Faria, A., Pintado, M., \& Calhau, C. (2013). Blueberry anthocyanins in health promotion: a metabolic overview. Journal of Functional Foods, 5(4), 1518-1528. http://dx.doi. org/10.1016/j.jff.2013.08.015.

Nunes, M. A., Costa, A. S. G., Barreira, J. C. M., Vinha, A. F., Alves, R. C., Rocha, A., \& Oliveira, M. B. P. P. (2016). How functional foods endure throughout the shelf storage? Effects of packing materials and formulation on the quality parameters and bioactivity of smoothies. Lebensmittel-Wissenschaft + Technologie, 65, 70-78. http://dx.doi. org/10.1016/j.lwt.2015.07.061.

Oliveira, M. I. S., Tonon, R. V., Nogueira, R. I., \& Cabral, L. M. C. (2013). Estabilidade da polpa de morango atomizada utilizando diferentes agentes carreadores. Brazilian Journal of Food Technology, 16(4), 310-318. http://dx.doi.org/10.1590/S1981-67232013005000037.

Paim, D. R. S. F., Costa, S. D. O., Walter, E. H. M., \& Tonon, R. V. (2016). Microencapsulation of probiotic jussara (Euterpe edulis M. ) juice by spray drying. Lebensmittel-Wissenschaft + Technologie, 74, 21-25. http://dx.doi.org/10.1016/j.lwt.2016.07.022. 
Peixoto, F. M., Fernandes, I., Gouvêa, A. C. M. S., Santiago, M. C. P. A., Galhardo Borguini, R., Mateus, N., Freitas, V., Godoy, R. L. O., \& Ferreira, I. M. P. L. V. O. (2016). Simulation of in vitro digestion coupled to gastric and intestinal transport models to estimate absorption of anthocyanins from peel powder of jabuticaba, jamelão and jambo fruits. Journal of Functional Foods, 24, 373-381. http:// dx.doi.org/10.1016/j.jff.2016.04.021.

Pontes, P. R. B., Santiago, S. S., Szabo, T. N., Toledo, L. P., \& Gollücke, A. P. B. (2010). Atributos sensoriais e aceitação de sucos de uva comerciais. Food Science and Technology, 30(2), 313-318. http:// dx.doi.org/10.1590/S0101-20612010000200004.

Re, R., Pellegrini, N., Proteggente, A., Pannala, A., Yang, M., \& RiceEvans, C. (1999). Antioxidant activity applying an improved ABTS radical cation decolorization assay. Free Radical Biology \& Medicine, 26(9-10), 1231-1237. PMid:10381194. http://dx.doi.org/10.1016/ S0891-5849(98)00315-3.

Rødbotten, M., Martinsen, B. K., Borge, G. I., Mortvedt, H. S., Knutsen, S. H., Lea, P., \& Næs, T. (2009). A cross-cultural study of preference for apple juice with different sugar and acid contents. Food Quality and Preference, 20(3), 277-284. http://dx.doi.org/10.1016/j. foodqual.2008.11.002.

Rufino, M. S. M., Alves, R. E., Brito, E. S., Morais, S. M., Sampaio, C. G., Pérez-Jiménez, J., \& Saura-Calixto, F. D. (2007). Metodologia científica: determinação da atividade antioxidante total em frutas pela captura do radical livre ABTS+. Comunicado Técnico, 128, 1-4.

Sabbe, S., Verbeke, W., Deliza, R., Matta, V., \& Van Damme, P. (2009). Effect of a health claim and personal characteristics on consumer acceptance of fruit juices with different concentrations of açaí
(Euterpe oleracea Mart.). Appetite, 53(1), 84-92. PMid:19467277. http://dx.doi.org/10.1016/j.appet.2009.05.014.

Santhirasegaram, V., Razali, Z., George, D. S., \& Somasundram, C. (2015). Comparison of UV-C treatment and thermal pasteurization on quality of Chokanan mango (Mangifera indica L.) juice. Food and Bioproducts Processing, 94, 313-321. http://dx.doi.org/10.1016/j. fbp.2014.03.011.

Schulz, M., Borges, G. S. C., Gonzaga, L. V., Seraglio, S. K. T., Olivo, I. S., Azevedo, M. S., Nehring, P., de Gois, J. S., Almeida, T. S., Vitali, L., Spudeit, D. A., Micke, G. A., Borges, D. L. G., \& Fett, R. (2015). Chemical composition, bioactive compounds and antioxidant capacity of juçara fruit (Euterpe edulis Martius) during ripening. Food Research International, 77, 125-131. http://dx.doi.org/10.1016/j. foodres.2015.08.006.

Singleton, V. L., \& Rossi, J. A. (1965). Colorimetry of total phenolics with phosphomolybdic-phosphotungstic acid reagents. American Journal of Enology and Viticulture, 16, 144.

Verma, S., Singh, A., \& Mishra, A. (2013). Gallic acid: molecular rival of cancer. Environmental Toxicology and Pharmacology, 35(3), 473485. PMid:23501608. http://dx.doi.org/10.1016/j.etap.2013.02.011.

Vojdani, A., \& Vojdani, C. (2015). Immune reactivity to food coloring. Alternative Therapies in Health and Medicine, 21(Suppl. 1), 52-62. PMid:25599186.

Wang, H., Hu, Z., Long, F., Guo, C., Niu, C., Yuan, Y., \& Yue, T. (2016). Combined effect of sugar content and $\mathrm{pH}$ on the growth of a wild strain of Zygosaccharomyces rouxii and time for spoilage in concentrated apple juice. Food Control, 59, 298-305. http://dx.doi. org/10.1016/j.foodcont.2015.05.040. 